\title{
Corporate Ethics: China vs. USA
}

\author{
Peng S. Chan, (E-mail: pchan@exchange.fullerton.edu), California State University, Fullerton \\ Dennis Pollard, (E-mail: dpollard@ fullerton.edu), California State University, Fullerton \\ Shirley Chuo, (E-mail: schuo@la.aiuniv.edu), American InterContinental University
}

\begin{abstract}
Fairness is one of the basic aspects of business exchange. Ethics are principles used to establish fairness. This study will look at background and origins for different American and Chinese ethical beliefs. It is important for U.S. and Chinese firms to understand each other's cultural perspectives, especially as the Chinese market opens up. Methods to resolve ethical conflict will be reviewed. Business agents from both cultures can relate and deal with each other if they have the knowledge, skills, and patience to do so. This study builds on prior research that suggests that younger Chinese are more concerned with profit than with abiding by regulations or adhering to corporate ethics. The major argument of this study is that future Chinese business leaders, born after China's onechild policy was implemented in 1979, will be primarily concerned with self-interest and making decisions that will benefit them individually. Guanxi (interpersonal connections or human relationships), corporate ethics and social responsibility (CESR) beliefs will be reduced in importance and influence. American managers should incorporate this information when formulating a "China strategy".
\end{abstract}

\section{INTRODUCTION}

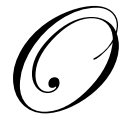

ne of the most fundamental aspects of business is fairness. When two parties meet to transact business each desires to obtain a product that is of least equal value for the item they are exchanging. Key to establishing value is the buyer and supplier receiving what they expect from each other. Fairness is subjective and shaped by many parameters such as personal preferences, relationships, culture, religion, philosophy, resources, and government. Ethics are the system principles used to establish fairness.

Debate over recent corporate scandals in the United States illustrates the broad range of ethical beliefs within a single culture. Business ethics are under scrutiny. Questionable practices that were overlooked in the past are now a primary concern. Companies must make ethics and compliance a central part of their strategic operating plan. There are ways to build an ethical culture and it must become part of the company and of those who work there. It takes careful thought, hard work, constant communication and consistency. Reinforcing positive values and clearly identifying expectations for ethical conduct are necessary. ${ }^{1}$

As the global market continues to expand and international business and trade become increasingly common, it is important that companies establish a code of ethics. The difficulties in establishing an ethical consensus multiply across international borders. It may be difficult and challenging, but ethics is a critical component of overall corporate performance. A company's strategic success is driven by a strong corporate culture founded on ethical business principles and moral values. An organization must care about how it does business; otherwise an organization's reputation and ultimately its performance may be at risk. Corporate ethics and values programs are implemented to create an environment of strongly held values and convictions and to make ethical conduct a way of life. ${ }^{2}$ Moral values and high ethical standards nurture the corporate culture in a positive way as they establish integrity and trustworthiness. These winsome characteristics bolster customer satisfaction and investor confidence, which enhance corporate value.

Conducting business across borders and across cultures is complicated as the nuances of acceptable behavior and standards can be hard to understand. Naturally, companies want to deal with firms that are ethical, honest, and reliable, but this may be difficult to identify. Different legal and cultural constraints make integrating an ethical 
component into international business dealings even more important and challenging. What is legal and generally acceptable in the United States may not be in China and vice versa. There are many differences in cultural norms and seemingly straightforward and forthright behavior from an American perspective may be considered improper and unacceptable by the Chinese. There is no single, universal code of ethics that is adopted by all people which makes cross-cultural relationships and transactions highly intricate and complicated. Research must be conducted prior to engaging in international exchanges and relationships for successful results.

With a potential market of over 1.2 billion people, China attracts marketer interest especially with the country's recent accession to the World Trade Organization at the close of 2001. Many Western businesses are anxious to enter the gates of the Chinese market, but they are not prepared for what awaits them. The Western capitalistic system is quite the opposite of China's communist system. Capitalistic and free-market ideas are contrary to China's socialistic system where the people are accustomed to a large degree of government ownership and control. Despite China's economic liberalization, market access is still challenging. To penetrate the Chinese market in a responsible manner, U.S. companies need to bridge the gap and figure out the complex ethical puzzle, which is deeply rooted in culture and tradition.

\section{PURPOSE OF STUDY}

The purpose of this study is to examine corporate ethics in the U.S. and China. The background and origins for ethical beliefs vary and they trace back many years in history. The differences are many, but the study will examine ways in which the two countries differ in their ethical values and how they can reach ethical understanding and respect. This study will look at how Chinese and American business executives view the role of ethics and explore how U.S. companies can reconcile the different ethical beliefs when negotiating with Chinese businesses. The trend for future executive behavior and ethical belief in China will also be considered.

\section{CULTURAL MAPPING}

To establish an understanding for the foundational differences in Chinese and American culture and ethics, a visual picture of American and Chinese moral philosophies is helpful. Robertson and Crittenden's study on crosscultural societal ethics suggests that the basis for ethics is found in the macro-level moral environment and in individual-level beliefs, both of which are built on moral philosophies. Economic ideology and national culture are two of the most basic influences organizations and managers face in an international setting. ${ }^{3}$ A cross-cultural map of the moral philosophies indicates the significant differences between Eastern and Western cultures (see Figure 1). The $\mathrm{x}$-axis shows culture and ranges a span from Western to Eastern and the $\mathrm{y}$-axis shows economic ideology that ranges from socialism to capitalism. The United States falls in the upper left corner of the map indicating a strong Western culture coupled with a strong capitalist economic ideology. Egoism is also found in this quadrant, which means the U.S. demonstrates a highly individualistic moral code. Sweden or Norway would fall in the bottom left corner as Western socialist cultures and Japan would fit in the top right corner with its Eastern values and capitalist economic system. Finally, the Eastern socialist quadrant in the bottom right corner is where China and utilitarianism fall on the map. The goal of utilitarianism is to seek the greatest good for the greatest number of people. To create personal gain at the expense of society's gain is considered unethical. In general, this philosophy is in accord with Chinese belief, but there are some conflicts in terms of individual business practices and ethics.

\section{CULTURAL ORIGINS AND DIFFERENCES}

Business transactions between Western and Chinese firms are affected by expectations within cultures. It is crucial for U.S. marketers to understand the expectations of their global partners. An inability to master the basic Chinese cultural factors will lead to business failure.

Cultural values are taught and communicated by parenting, socialization, education, and religion. Other factors include differences in the systems of laws across countries, accepted human resource management systems, organizational culture, and professional cultures. A problem arises for managers engaged in cross-cultural transactions when cultures view behavioral practices with different levels of condemnation. How is a manager to deal 
with differences in ethical behavior that originate from differences in culture? Just because a course of action is legal, does not mean it is ethical. ${ }^{4}$ This issue must be dealt with before it becomes a problem.

Examples of individual or organizational misconduct include illegal campaign contributions, bribery, knowingly selling defective goods, hiding information, and insider trading. In these instances an ethical framework is not followed. In the U.S., The Foreign Corrupt Practices Act was enacted to prevent U.S. companies, no matter their worldwide location, from engaging in any activities that are illegal in the U.S. For instance, bribery is forbidden to obtain business for any U.S. company even if the transaction occurs outside of U.S. borders.

In China, bribery may be considered somewhat acceptable in business. Sometimes knowing whom to pay to ensure that a deal goes smoothly is very important and those who do not may face frustration and obstacles. If a U.S. company engages in bribery, it must hide it, while in contrast China may be more tolerant of such practices. A country's culture is directly related to the ethical behavior of its managers. ${ }^{5}$ This includes overt actions such as public or corporate statements and actions about ethical behavior and the collection of group ethical attitudes and values.

Culture is difficult to define universally as it represents a group's values, patterns of thinking, feeling and acting. Culture represents how people in a civilization interact with each other.

Official lists and codes of conduct detailing prohibitions and acceptable practices are helpful to managers when they make decisions, however they are not enough to govern cross-cultural ethical interaction. In China, giving a carefully chosen business gift communicates great respect and indicates that the giver values the business relationship. So not only is the practice acceptable, it is encouraged to promote good business. On the contrary, some U.S. firms like banks may not allow their employees to engage in any sort of gift exchange. Even accepting something as simple as a promotional coffee mug may be against corporate policy. Such rules are instituted to prevent bribery or gifts with the purpose to influence a decision-maker's judgment. Conflict arises when standards such as these are different.

To reconcile the differences in the way business people in each country think and behave we have to understand the origins of their beliefs. ${ }^{6}$ In the U.S., ethical beliefs are mostly based on a foundation of traditional Judeo-Christian and Western socio-theological laws and principles. At the core is the belief in an intrinsic underlying truth, which is central to the biblical system of morality and ethics. God is considered the sovereign moral authority who decrees what is right and wrong, and provides a general moral and legal code for societal structure.

Similarly, founding fathers of the U.S. established and affirmed an individual's "inalienable rights" to life, liberty, and the pursuit of happiness. All people were considered equal under the law. It is important to note that the right to choose is the foundational belief upon which open, competitive markets have been established as the best way to operate the economy. This type of market system is beneficial because it allocates resources in what is considered the most favorable way. At the same time, this system is designed to satisfy the needs of the collective society, but not necessarily the needs of a single individual or a particular group.

In the U.S., business contracts explain the particulars and the nature of a business relationship along with the obligations of each party involved. It is the norm that these commitments are honored to the letter and the spirit of the contract. Once people enter a contract they are bound to it. This is both a legal and an ethical commitment by both parties and reflects the underlying belief in truth. Business agents will attempt to engage in transactions that are the most beneficial to them and the parties they represent. The signing of a contract is often viewed as the final stage of association for a business.

Chinese business ethics is influenced by several factors. They believe that everything should be in harmony, taking the long-term view on things. If changes will be disruptive and significant, the Chinese would prefer not to take action rather than to take action. This belief has its roots in Confucianism and Taoism. Harmony is emphasized to preserve peace and societal order and have clearly impacted the way Chinese think and behave. Negotiations and contracts link people by reinforcing the human bond more than the legal binding. Chinese managers see contracts as the first step to a deeper business relationship with a business partner. 
Efficiency and effectiveness are strong American beliefs that may come across as abrupt and inharmonious to Chinese. Americans value the desired end result and are willing to engage in competition and quick action to achieve it. This may be a source of conflict in Chinese-American business relationships.

Interpersonal connections or human relationships are called guanxi in the Chinese language. Such relationships and human feelings are very important, as the Chinese mentality is to work together in groups to accomplish a goal. The individual does not get much attention and is not singled out as important. There are three main types of guanxi: family guanxi, helper guanxi, and business guanxi. Family guanxi and helper guanxi can be described as special emotional ties and instrumental/utilitarian ties, respectively. Business guanxi is a process whereby personal connections are used in the process of finding a solution to a business problem instead of a personal problem. $^{\text {? }}$ The types of guanxi are quite different in nature, purpose, function and what is exchanged. Business guanxi is utility-driven having to deal with money and power, which is the result of current political and socioeconomic systems. Business guanxi is tactical, opportunistic and relatively unstable with less commitment and trust. What matters most to the parties is their own business interest. Guanxi emphasizes "the rule of man" more than it does "the rule of law" and this helps to explain why Chinese executives and entrepreneurs constantly build and maintain their guanxi networks. These connections can be very powerful and they extend to other individuals and companies. At the same time, guanxi is a potential source of ethical conflict between Western and Chinese firms because Americans consider "the rule of law" to have more authority than human relationships.

The role of relationship networks to Americans is important for business, but they are more subtle. Business relationships are more easily separated from personal relationships because of the use of legal contracts. Americans may make friends more openly and easily, but they may be somewhat superficial. Relationships are more long-term for Chinese and they generally enter into relationships more gradually. Westerners are more up-front and frank about pursuing business deals while Chinese act with much more self-control in business situations and are more indirect and subtle. These different approaches can create frustration between parties. With an increasing number of companies trying to penetrate the Chinese market, relationship marketing has become critically important for business between U.S. and Chinese companies. A thorough understanding and development of guanxi is needed for U.S. companies to access the Chinese market.

Communication styles can also create conflict between Westerners and Chinese. Chinese believe that silence is golden and reserved for reflection and careful thinking. They usually do not talk too much because they feel the more they talk the more mistakes they will make. Americans on the other hand feel uncomfortable when there is silence in a conversation. This can be misinterpreted as a break in communication, but it is just a difference in cultural values.

In negotiations, Americans openly discuss advantages, disadvantages, and alternatives. Chinese business agents discuss and bargain as well, but they try to establish common feelings or bonds between the parties. They try to establish a win-win goal situation so that both parties can win and reap benefits. A one-sided negotiation where the winner takes all is unethical to the Chinese. ${ }^{8}$

\section{RESOLUTIONS FOR ETHICAL CONFLICT}

Considering the many differences, what are some strategies for resolving American-Chinese ethical conflicts? There are several suggestions for resolution and some are more positive in nature than others. One way to deal with difference is avoidance, which is often used in families and business relationships. In this situation, the parties may choose to ignore the problem, hoping that it will end or resolve itself. This is a useful strategy for the stronger of the two partners and especially useful if confrontation costs are high. An agent may take part in unethical activities, but confronting this issue may result in lost sales or market share. Therefore, the more powerful party can maintain the status quo with a "don't ask, don't tell" position.

The second way to resolve ethical conflict is by forcing one party's will on the other. This only works for the stronger party, which can make demands. One example is where importers with special access to domestic markets can demand certain things from their suppliers. This works well where markets are difficult to access by foreign firms 
and outsiders have little power. In such a relationship, the Chinese partner can force the U.S. firm to do things in a particular way.

Another resolution strategy is to use a combination of education and persuasion. This is a positive way to resolve conflict as U.S. businesses with operations in foreign countries have the opportunity of explaining the benefits of employee safety and human resources management regulation. This strategy is advantageous because it encourages communication between partners. The fourth possibility is infiltration, which refers to the spread of an idea in a society. The U.S. introduced various marketing ideas such as customer focus and high product quality in to several cultures. Negotiation and compromise is yet another strategy based on communication. Through communication, a settlement is reached. But in this situation, both parties may have to give something up and may feel dissatisfied with the outcome.

Accommodation is the next strategy and this takes place when one party adapts to the ethic of the other. A Chinese company may agree and comply with the ethical view of the U.S. partner in order to obtain business. Collaboration is the final strategy and probably the most desirable resulting in the best outcome. By collaborating and using a problem-solving strategy, both parties can work together to formulate a mutually beneficial and acceptable solution. This strategy is most likely to bridge the ethical differences separating the parties while building trust. The focus is on uncovering or addressing problems in the ethical relationship and solving them in such a way that both partners are satisfied. Each of the alternative strategies may be appropriate to deal with a particular ethical conflict. No conflict reduction strategy is necessarily better than another and each one may be suitable in a specific case. ${ }^{9}$

\section{THE ROLE OF CORPORATE ETHICS IN BUSINESS STRATEGY}

Ethical company practices are more than just the cost of doing business. Ethical practices are a business imperative because they affect investor confidence and long-term competitiveness. The collapse of Enron and the scandal involving MCI WorldCom demonstrate the ravaging effects of unethical behavior all too well. Investor and legislative sensitivity are high and once a company loses the respect and support of its investors its value and position are bound to crash. Ethics are also a legal necessity. The recent Sarbanes-Oxley Act of 2002 requires American CEOs and CFOs to personally certify the accuracy of company financial statements. Corporate executives and managers may no longer use "I didn't know about it" as an excuse for unethical practices. They will be expected to know what is happening in their companies and will be bound to it. Company performance should reduce the focus on short-term profits and stock performance and instead emphasize long-term success by building credibility in the financial community, hiring ethical employees, and creating an ethical culture.

Most employees want to "do what's right", however they can run into trouble if they believe their company expects them to act unethically. Senior managers often reward and commend employees who can solve problems, but management needs to know how problems are being solved. Management and employees need to be able to communicate about problems, raise issues, and ask questions; otherwise employees may engage in undesirable activities and behaviors. ${ }^{10}$ Oftentimes employees unintentionally violate company policies out of ignorance. They commit small gray area violations that can build up and become major ethical problems. Thus, company-wide ethical guidelines and policies need to be clearly communicated, practical, comprehensive, and enforced. ${ }^{11}$

\section{THE CHINESE ETHICAL PERSPECTIVE}

The differences in ethical perspective between American and Chinese businesses pose a challenge to American firms that want to penetrate the Chinese market. In the U.S. self-interest is tempered as companies are prohibited from illegal behaviors, and recently, greater emphasis has been placed on ethical behavior, but how do Chinese business agents perceive the role of ethics in their business operations?

A survey by Chan, Cheng and Szeto (2002) suggests that younger Chinese executives and those working for privately owned firms and joint ventures are more inclined to take part in unethical activities for profit. ${ }^{12}$ This information provides useful insight into what factors U.S. and international corporations should use to identify the types of employees needed in China. If more profit-oriented employees are needed, a company may consider hiring 
younger people, keeping in mind that they may also be less ethical. The information from the survey is also helpful in determining strategies for minimizing ethical conflicts. If a U.S. corporation wants to hire executives that are more likely to follow regulations, older executives of state-owned companies would be desirable candidates. ${ }^{13}$

There is consensus about China's moral philosophy as a utilitarian country. ${ }^{14} 1516$ But there are exceptions. Overall, China is a utilitarian country as individuals behave and conduct themselves more or less according to the principles of guanxi. The well-being of the group is emphasized, but there seems to be an increase in self-interest as well. Younger executives tend to be more interested in making profits instead of abiding by the law or emphasizing friendship as evidenced by the study done by Chan, Cheng, and Szeto. An apparent syndrome of selfishness has taken hold of corporations and society. ${ }^{17}$

China is in a unique situation as its communist government makes efforts to liberalize and open its vast market to foreign companies. Ideologically, it seems contradictory, but it provides great business opportunity. Interestingly enough, research conducted by Ang and Leong (2000) on Chinese undergraduates in Hong Kong and Singapore indicate that guanxi is likely to have a negative impact on corporate ethics and social responsibility (CESR) beliefs. The loyalty guanxi implies is to another member of the guanxi network, which forgoes consideration for the "greater good" or society in general. ${ }^{18}$ The study done by Ang and Leong surveyed Chinese business undergraduates from Hong Kong and Singapore about their beliefs on different business practices. It was found that CESR beliefs were negatively related to guanxi and that CESR beliefs were also weaker among Hong Kong youths than among Singaporean youths.

\section{IMPLICATIONS FOR DOING BUSINESS IN CHINA}

China is closely tied to Hong Kong commercially and socially, and their ways of conducting business is similar. This implies that Chinese youth in China may have similar corporate ethics and social responsibility (CESR) beliefs. The studies conducted by Chan et al and Ang \& Leong examine Chinese opinions on guanxi, business, and ethics and both studies determined that younger Chinese have a tendency to be less concerned about ethics and more concerned about profits, self-interest, and guanxi.

These studies do not offer what the likely trend will be in terms of Chinese business and ethical practices after World Trade Organization accession and over the long term. The present study builds on the previous research and suggests that China's future business leaders will become more focused on self-interest and profit and less concerned with guanxi and CESR as today's Chinese youth become tomorrow's business executives and leaders.

China's one-child policy and growing wealth has resulted in social and economic changes. Chinese couples are choosing to create their own homes separate from parents and in-laws as the traditional system of living with the husband's parents is dying out. More married women are working outside the home, which increases disposable family income. There is a shift away from Confucian norms that promote the welfare of the larger kin group and aging parents to norms that promote the individual immediate families. These changes have weakened the traditional family structure. ${ }^{19}$ Parents lavish their only child (singletons) with money and attention. Since 1979, China's singlechild family policy has helped produce a generation of "little emperors and empresses". They are given the undivided affection and economic support of two working parents and four grandparents. They are encouraged to study hard and to excel in school. Families pamper and cater to these children giving them considerable power to influence buying decisions. ${ }^{20}$

The first singletons born are now in their mid-twenties and should be in the early stages of their careers. They are accustomed to getting whatever they want and having things their way since they were brought up under these conditions as children. Poised to become China's future executives and business leaders, these young Chinese represent a new generation that is more self-interested and less inclined to follow more traditional norms of filial piety and guanxi, as well as, corporate ethics and social responsibility (CESR) beliefs. Often they will be motivated to make choices that serve themselves and this will be apparent in their business decisions. In time, guanxi traditions should become less of an issue as China gravitates towards a more free market economy with increased opportunities for foreign trade and investment. 


\section{CONCLUSION}

From this study we have learned that Chinese business leaders will be more competitive and profit oriented as singletons enter the job force. This is important for American corporations to know so that they can prepare appropriate strategies to use in their China based business relationships. American managers must take note that codes for ethical conduct may not be well developed or well enforced by Chinese based businesses and employees so they should proceed with caution in their business dealings. Thorough understanding of China's cultural system will help in business transactions and in developing relationships with individuals and firms. The conflict resolution strategies presented earlier are helpful when addressing ethical conflicts.

Fairness is one of the basic aspects of business and ethical principles are used to establish fairness. Corporate ethics plays a very important role in business strategy because they are directly tied to investor confidence and longterm competitiveness. As China opens up with attractive business opportunities, U.S. companies need to understand Chinese culture and ethical beliefs, which can be very different. Conflicts are bound to occur when conducting crosscultural business transactions, but they can be minimized with some background research, communication, and collaboration. Mutually beneficial outcomes can be reached if the partnering firms work together.

Studies have shown that younger Chinese tend to favor profits and self-interest over friendship and legal restrictions. This study takes these findings a step further and examines what behaviors can be expected from future Chinese business leaders. This study reveals the likely trend in up and coming business leaders who were raised as singletons (only children) born after 1978. These individuals are accustomed to getting their own way and will most likely make self-interest a priority above all else. Guanxi and corporate ethics and social responsibility (CESR) beliefs will probably play a diminished role as singletons take charge. This is important for U.S. companies to know as they develop their cross-cultural Chinese-American business strategies.

Further research needs to be conducted regarding the attitudes of youths in China towards ethics and what role it should play in business and society. Social and economic changes have affected people's outlook, and it would be useful to know what is important to young people and what they think and feel about Chinese tradition, guanxi, and the law. Young people today will have a major impact on China's business environment in the future.

FIGURE 1: CULTURAL MAP

Focus of research propositions Moderating variables

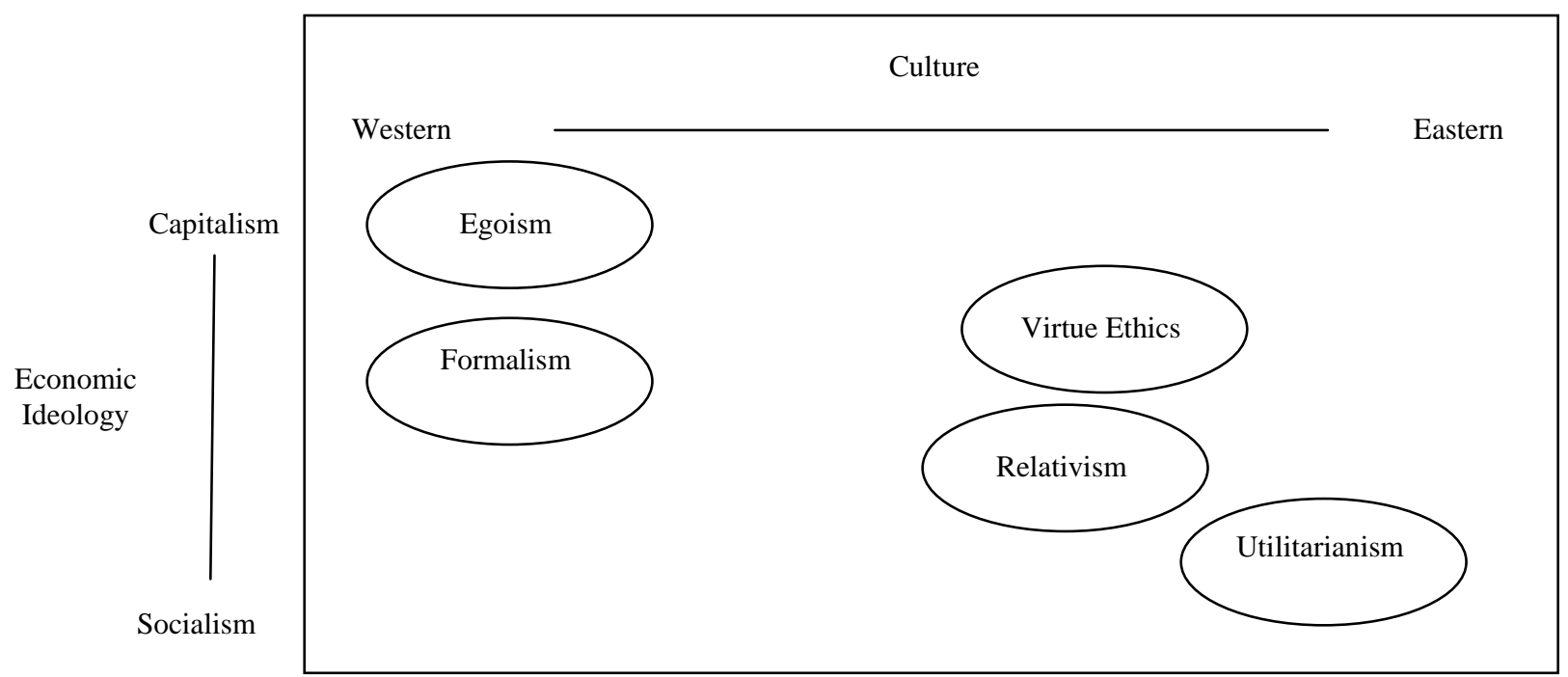

Source: Roberson and Crittenden, Mapping Moral Philosophies: Strategic Implications for Multinational Firms, Strategic Management Journal, 24: 389 (2003). 


\section{ENDNOTES}

${ }^{1}$ Hayes, Troy. The New Bottom Line for Business Executives: Today, Ethics, Not Numbers, Deserve Business Leaders' Greatest Attention, Journal of Business Strategy, 23, 6, Nov-Dec 2002: 34.

${ }^{2}$ Thompson, Jr., Arthur, J. Gamble, and A. Strickland, III. Strategy. New York, NY: McGraw-Hill/Irwin, 2004.

${ }^{3}$ Robertson, Christopher and William Crittenden. Mapping Moral Philosophies: Strategic Implications for Multinational Firms, Strategic Management Journal, 24, 2003: 388.

${ }^{4}$ Barry, Megan. Why Ethics \& Compliance Programs Can Fail: Set It and Forget It, Journal of Business Strategy, 23, 6, Nov-Dec 2002: 38.

${ }^{5}$ Pitta, Dennis, Fung, Hung-Gay, and Isberg, Steven. Ethical Issues Across Cultures: Managing the Differing Perspectives of China and the USA, The Journal of Consumer Marketing, 16,3, 1999: 242.

${ }^{6}$ Pitta, Fung, and Isberg, 244.

${ }^{7}$ Fan, Ying. Guanxi's Consequences: Personal Gains at Social Cost, Journal of Business Ethics, 38, 4, July 2002: 371.

${ }^{8}$ Pitta, Fung, and Isberg, 251.

${ }^{9}$ Pitta, Fung, and Isberg, 254.

${ }^{10}$ Barry, 37.

${ }^{11}$ Hayes, 34.

${ }^{12}$ Chan, Ricky, Cheng, Louis, and Szeto, Ricky. The Dynamics of Guanxi and Ethics for Chinese Executives, Journal of Business Ethics, 41,4, Dec 2002: 327.

${ }_{13}^{13}$ Chan, Cheng, and Szeto, 333.

${ }^{14}$ Robertson and Crittenden, 388.

${ }^{15}$ Fan, 371 .

${ }^{16}$ Chan, Cheng, and Szeto, 328.

${ }^{17}$ Mintzberg, Henry, Simons, Robert, and Basu, Kunal. Beyond Selfishness, MIT Sloan Management Review, 44, 1, Fall 2002: 67.

${ }^{18}$ Ang, Swee Hoon and Leong, Siew Meng. Out of the Mouths of Babes: Business Ethics and Youths in Asia, Journal of Business Ethics, 28, 2, Nov 2000: 133.

${ }^{19}$ Watson, James L. China's Big Mac Attack, Foreign Affairs, 79, 3, May/Jun 2000: 126.

${ }^{20}$ Johnstone, Helen. Little Emperors, Call the Shots, Asian Business, 32, 9, Sep 1996: 67. 